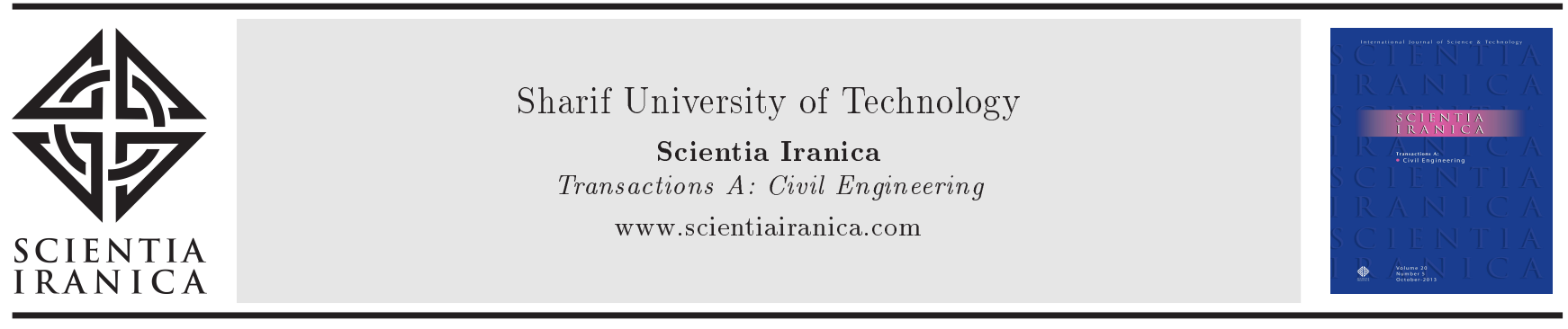

\title{
Selection and scaling of spectrum-compatible ground motion records using hybrid coded genetic algorithms
}

\author{
S. Yaghmaei-Sabegh ${ }^{a, *}$, S. Karami ${ }^{b}$ and M. Hosseini-Moghadam ${ }^{b}$ \\ a. Department of Civil Engineering, University of Tabriz, Tabriz, Iran. \\ b. East Azarbaijan Science \& Research Branch, Islamic Azad University, Tabriz, Iran.
}

Received 22 June 2015; received in revised form 22 November 2015; accepted 25 April 2016

\author{
KEYWORDS \\ Ground motion \\ scaling; \\ Time history analysis; \\ Design spectrum; \\ Genetic algorithm; \\ Hybrid-coded genetic \\ algorithm.
}

\begin{abstract}
This paper presents a new searching framework for optimal scaling of earthquake ground motion records as inputs for dynamics analysis. Two hybrid-coded Genetic Algorithms (GA), named real-permutation and binary-permutation GA, are effectively used to solve an applicable optimization problem in earthquake engineering field. Methodologies are outlined to choose a set of ground motions, with a good level of fit to the design spectrum, and the corresponding scales simultaneously during a hybrid-coded process. The effects of different parameters used in design of algorithms are investigated through sensitivity analysis to suggest a set of proper input values. Analysis showed that the sensitivity of the binary-permutation GA results to input parameters variations is less than that of real-permutation GA. The paper also concludes that binary-permutation GA is slightly more reliable than real-permutation GA; accordingly, it is recommended as a suitable algorithm to select and scale spectrum-compatible ground motion records.
\end{abstract}

(C) 2017 Sharif University of Technology. All rights reserved.

\section{Introduction}

Nowadays, time-history dynamic analysis is vastly used by the growth of computer processors as an accurate and complete tool in seismic design and performance evaluation of buildings. Most design codes, as Iranian seismic design code (Standard No. 2800 [1]), require a time-history dynamic analysis as an efficient method for seismic design of high-rise buildings and important structures, at least. To perform time-history analysis, seismic actions are described by a suit of ground motion records. The predicted seismic demands are highly dependent on ground motion characteristics used in the analyses. Hence, employing appropriate accelerograms is becoming increasingly important to

\footnotetext{
*. Corresponding author. Tel: +98411 339-2402; Fax: $+98411334-4287$

E-mail addresses: s_yaghmaei@tabrizu.ac.ir (S. Yaghmaei-Sabegh); samane.k.org@gmail.com (S. Karami); mazdak.hm@gmail.com (M.Hosseini-Moghadam)
}

reach an accurate and realistic response, particularly in the range of nonlinear behavior [2-7]. A large body of literature exists on scaling and selection of ground motion records; however, some challenges emerged in some practical nonlinear dynamic analyses applications, such as how to select appropriate set of records or how many records should be used for analysis [814]. Ground motions that are used in the timehistory dynamic analysis should be the representation of regional seismicity at the site of interest $[4,5,15]$. To reach a set of ground motion records compatible with a hazard-consistent design spectrum, selected records should be scaled appropriately as adopted by most of the seismic design codes $[6,16,17]$. As a conventional procedure, compatibility of the $5 \%$ damped average response spectra of the selected records with design-code response spectrum, Uniform Hazard Spectrum (UHS), or Conditional Mean Spectrum (CMS), is controlled in the specific range of the vibration period $[4,5,18]$. Ground motion records used in dynamic analysis can be categorized as real or simulated records. The 
use of simulated ground motions plays an important role in seismic hazard analysis, particularly for the cases with insufficient population number of recorded ground motions for the study region. Several different methods have been proposed by seismologists for ground motion simulation, among which stochastic methods are one of the efficient and most widely used approaches $[19,20]$.

Different methods, presented in the past for scaling of earthquake ground motion, can be summarized as frequency domain methods [21-23]. In the frequency domain strategies, frequency content of the ground motions records is manipulated in order to obtain a reasonable match where in time domain methods, amplitude of earthquake records is manipulated through the analysis [24,25]. The most important parameters in the records selection procedures are: magnitude, source-to-site distance, rupture mechanism, soil type, and duration of the earthquake. Shome et al. [8] chose a set of real accelerograms based on four different conditions of the magnitude and distance measures for nonlinear time-history analysis of a 5-storey building. Bommer and Acevedo [7] and Stewart et al. [26] assumed magnitude as the most important parameter in the selection procedure of earthquake records. Iervolino and Cornell [10] studied the dependency of the structure response on the magnitude and distance parameters. In their research, real records are divided into two main categories and compared with each other in different modes. The first category is precise selection of record with specific magnitude and distance from the site; the second category includes the random selection in a large database. Some other researchers examined the effect of soil condition on the selection of compatible-spectrum records $[27,28]$.

Selecting and scaling earthquake records compatible with the target spectrum (a spectral matching in frequency domain) can be considered as a constrained optimization problem, which can be solved using different algorithms. By increasing the computational power of engineering software, different stochastic optimization algorithms, including genetic algorithm [4], simulated annealing [29], particle swarm [30], and harmony search $[3,31]$, are vastly used in the optimization of the process of problem solving. In 2004, Naeim and co-workers developed a genetic-based method for selecting and scaling the earthquake records matched with target design spectrum [4]. They used a binarycoded genetic algorithm that treats any random union of 7 records and corresponding scale factors as a single "individual". The best Mean Square of Error (MSE) was calculated as $3.1 \%$ for the obtained ground motion datasets in the period range of 0.25 to $1.89 \mathrm{sec}$ [4]. It is clear that the nature of the number of earthquakes in dataset and corresponding scale factors is different. For this reason and as a new innovation in GA-based solution for selecting and scaling of ground motions among a complex search space, the proposed genetic algorithms serve two chromosomes separately. The first chromosome is considered for the selection of records number where the second chromosome performs the updating process of scale factors. Indeed, the hybridcoded nature of the genetic algorithm is a distinct characteristic of this study which increases computational efficiency, taking a step forward to reduce the error rate of analysis. As a result, two different hybrid-coded algorithms are developed herein: (I) realpermutations and (II) binary-permutation coded GA. Records taken into consideration are selected from the ground motion records of real earthquakes obtained in the past. For this purpose, a set of 374 horizontal strong ground motions recorded at rock sites (soil type II) is selected from the Peer Ground Motions Database [32]. Target spectrum corresponding to very high seismic condition is adopted according to Standard No. 2800. The results of optimization procedure include 7 records and related scale factors, so that the average of the selected recorded response spectrum has the minimum differences with the selected target spectrum. Effects of the input parameters on the results and the degree of errors are obtained through the sensitivity analysis to answer this question that how sensitive the proposed algorithms to input parameters are.

\section{Genetic algorithms}

A genetic algorithm is a special kind of evolutionary algorithm and artificial intelligence that uses biology techniques, such as inheritance and mutation, to find appropriate answers. A Genetic Algorithm (GA) is a tool by which machines can perform a simulation mechanism of natural selection and model the mechanisms of genetic evolution [33]. The main characteristic of GA as a stochastic search algorithm is produced based on the principles of survival adoption and fittest [34]. Implementation of genetic algorithms begins by creating an initial population of chromosomes. The next step after generation of the initial population is choosing two parents and combining them into mating pool, which eventually provide one or two children and mutation of new offsprings. New child replaces one of his weaker counterparts in the population. Then, the initial structures were evaluated and given a chance to reproduce based on their capability. The suitability of the solution is commonly determined according to the current population.

The problem space is interpreted as the search space and includes all possible solutions to the problem. The genetic algorithms are normally used in problems in which the search space is large and the typical search methods could not be used simply for them. 
Genetic operators are used during the reproductive of each stage in GAs. The population of the next generation is produced via the effect of this operator on a population. The parameters of selection, crossover, and mutation are the most used operators in genetic algorithms. The crossover operator has performed mating on two-parent (or more) chromosomes and has produced two children for the new generation. If the selected chromosomes had better properties, they would have a higher chance to obtain the optimal solution by less iteration. The mutation operator is applied to expand the population and generate new search points. The usage rate of this operator is important. If the mutation probability was too much, the algorithm would lose its ability to converge the optimal solution. On the other hand, if the low value of mutation rate was chosen, the algorithm would trap in local optimal or increase premature convergence due to the lack of genetic diversity. Hence, setting the mutation rate is important for genetic algorithms.

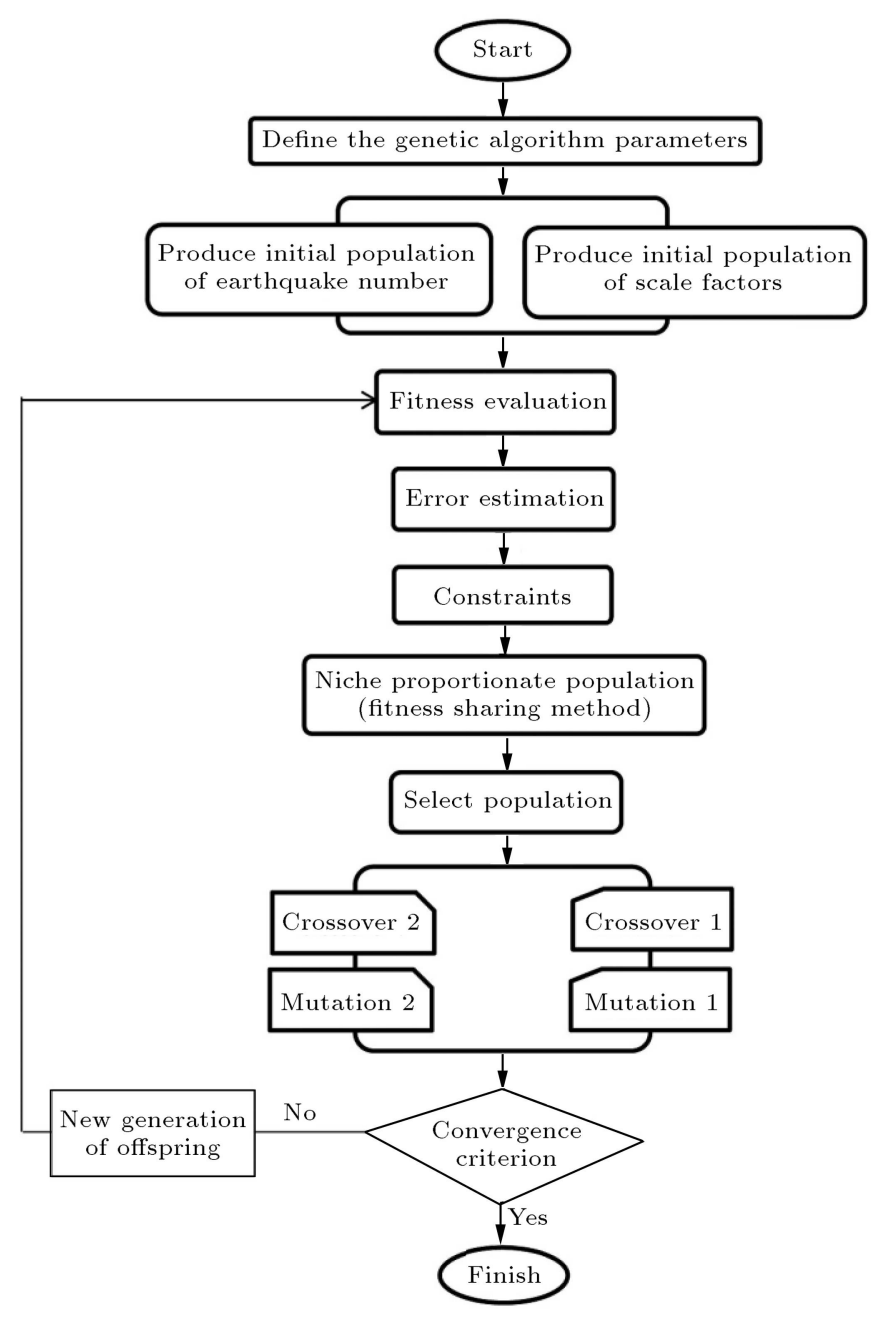

(a)

\section{Key features of the proposed approaches}

In the current work, two hybrid-encoded GA approaches as a new contribution are incorporated into the ground motion records selection procedure. These methods are named simply as hybrid genetic algorithm in this paper; however, it is different from those methods that combine GA with other searching methods. The first algorithm is the combination of real and permutation-coded genetic algorithms, where binary and permutation genetic algorithms are jointed in encoding process of variables in the second hybrid algorithm. As a difference, weighted average and uniform crossover techniques are respectively used for the first chromosome of real-permutation and binarypermutation algorithms to assign them to scaling factors. Figure 1 shows a diagram which simply describes the computation procedure of the first and second algorithms used in this paper.

In this section, detailed information about encoding process is given for the proposed GA. Binary

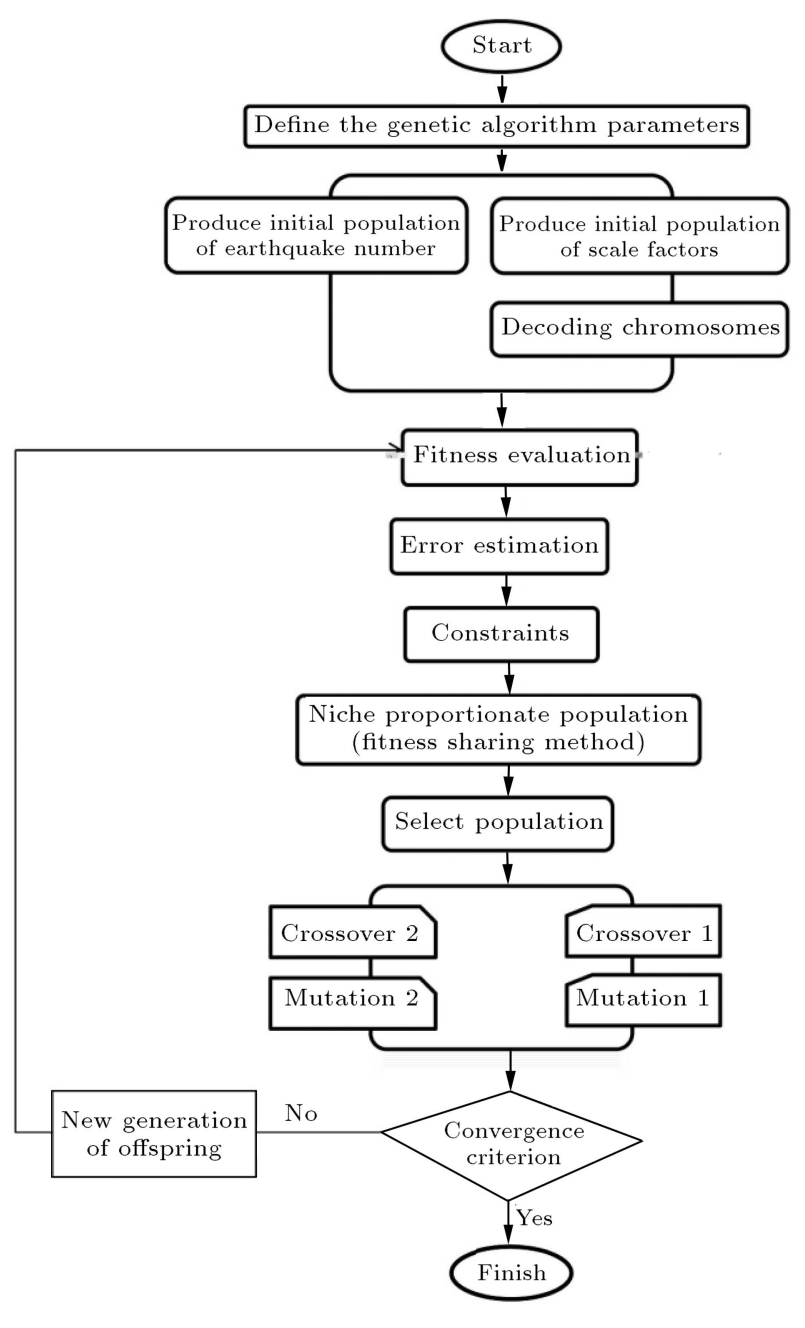

(b)

Figure 1. (a) Block diagram structure of real-permutation genetic algorithm. (b) Binary-permutation genetic algorithm. 


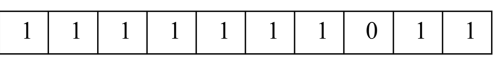

(a)

\begin{tabular}{|c|c|c|c|c|c|c|c|c|c|c|c|c|c|c|c|c|c|c|c|c|c|c|}
\hline \multicolumn{23}{|c|}{ Crossover location } \\
\hline Par1 & 1 & 0 & 1 & 1 & 0 & 0 & 0 & 1 & 0 & 1 & & Off1 & 1 & 0 & 1 & 1 & 1 & 0 & 1 & 0 & 1 & 1 \\
\hline \multicolumn{23}{|c|}{ Crossover $\rightarrow$} \\
\hline Par2 & 0 & 0 & 1 & 0 & 1 & 0 & 1 & 0 & 1 & 1 & & Off 2 & 0 & 0 & 1 & 0 & 0 & 0 & 0 & 1 & 0 & 1 \\
\hline
\end{tabular}

(b)

\begin{tabular}{|c|c|c|c|c|c|c|c|c|c|c|}
\hline \multicolumn{10}{|c|}{$\begin{array}{c}\text { Location of } \\
\text { mutation } \\
\downarrow\end{array}$} & \multirow[b]{2}{*}{ Before mutation } \\
\hline 1 & 0 & 1 & 1 & 0 & 0 & 1 & 0 & 1 & 0 & \\
\hline 1 & 0 & 1 & 0 & 0 & 0 & 1 & 0 & 1 & 0 & After mutation \\
\hline
\end{tabular}

(c)

Figure 2. (a) Binary chromosome representation. (b) Single-point crossover for binary GA. (c) Mutation for binary GA.

\begin{tabular}{|l|l|l|l|l|l|l|}
\hline 174 & 145 & 211 & 178 & 87 & 64 & 62 \\
\hline
\end{tabular}

(a)

\begin{tabular}{|c|c|c|c|c|c|c|c|c|c|c|c|c|c|c|c|c|}
\hline Parent1 & 174 & 145 & 211 & 178 & 87 & 64 & 62 & Crossover & Offspring 1 & 174 & 87 & 178 & 364 & 211 & 64 & 104 \\
\hline Parent 2 & 349 & 87 & 178 & 364 & 211 & 55 & 104 & & Offspring2 & 349 & 145 & 211 & 178 & 87 & 55 & 62 \\
\hline Mask & 1 & 0 & 1 & 0 & 0 & 1 & 0 & & & & & & & & & \\
\hline
\end{tabular}

(b)

Figure 3. (a) Representation of permutation chromosome. (b) Partially matched crossover used for permutation chromosomes.

encoding is used in binary-permutation to assign the scaling factors in this study. In this procedure, scale factors are presented by binary strings of bits, 0 or 1 . Each chromosome is broken to develop a gene based on the length of the string (or bits), taken as 10 herein. It is noted that conventional genetic algorithm operates on the fixed-length character strings; however, string length possibly reflects the level of accuracy or range of the individual variables. Figure 2 shows the representation of a particular individual of binary chromosome. In decoding procedure, a string is converted into an integer. Hence, the bit string is converted from binary to decimal form and normalized to values between 0 and 1 . The process is calculated for the $i$ th chromosome $\left(x_{i}\right)$ that contains $L_{i}$ bits as follows:

$$
\begin{aligned}
\left(x_{i}\right)_{10}= & \operatorname{bit}(0) \times 2^{0}+\operatorname{bit}(1) \times 2^{1}+\operatorname{bit}(2) \times 2^{2}+\ldots \\
& +\operatorname{bit}\left(L_{i}-1\right) \times 2^{\left(L_{i}-1\right)}=\sum_{k=0}^{L_{i}-1} \operatorname{bit}(k) \times 2^{k},
\end{aligned}
$$

where $b i t(k)$ represents the bit value at the $k$ th position in a decimal string.

Then, two chromosomes, selected as parents for crossover, will generate new offspring. Figure 2 illustrating uniform crossover has been adopted for binary GA in this paper to produce a new offspring. Finally, for mutation of an individual, the bit string is changed to 0 and 1 depending on its initial bit string.

Permutation encoding has been applied to select record numbers in the proposed binary-permutation algorithm. It is worth noting that, in permutation encoding, each of chromosomes is considered as a string of numbers, representing a number in a sequence. Permutation representation for an initial individual, including seven variables, is depicted in Figure 3 . Figure 3 shows the crossover process used for record number selection in permutation chromosomes. The real-permutation GA is performed similar to binarypermutation GA with a difference where chromosomes in real-permutation GA are integer, and there is no need to convert the values.

\section{Formulation of the problem}

The database used in this study contains 374 real earthquake ground motions from shallow crustal events. The dataset includes earthquake records obtained at rock 


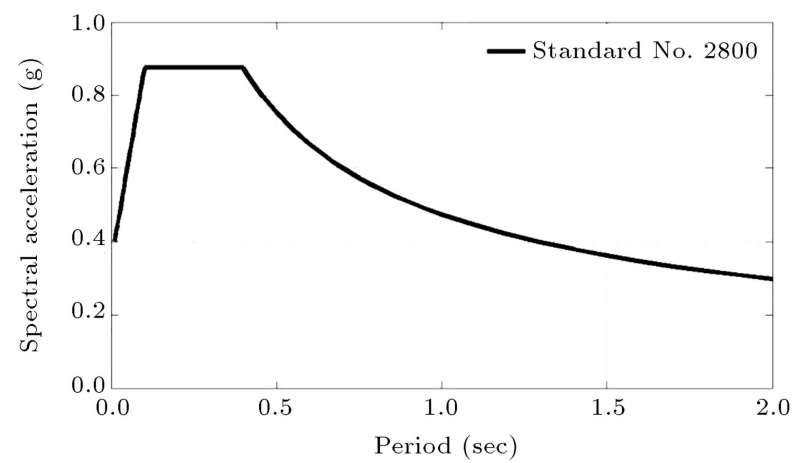

Figure 4. Code design spectrum (Standard No. 2800 [1]) selected as target spectrum.

sites with average shear wave velocity of 360 to 750 $\mathrm{m} / \mathrm{sec}$ in the top $30 \mathrm{~m}$ soil layers, corresponding to soil class II in Standard No. 2800. Acceleration spectral ordinates for damping ratio of $5 \%$ are obtained and used in the analysis. Target spectrum has been selected according to Standard No. 2800 for the regions with very high seismicity condition and design acceleration of $0.35 \mathrm{~g}$ at soil site class II (Figure 4).

Selection of 7 spectrum-compatible records and corresponding scale factors is considered as an optimization problem herein. In this regard, GA as an efficient tool is utilized to find an optimum solution by minimizing the error (or difference) between average spectrum of records and target spectrum in a specific range of period.

At first, all of records in database are scaled based on the value of $T_{0}$. Eq. (2) is used for this purpose as:

$$
S B_{i}(T)=\beta_{i} \times S A_{i}(T)
$$

the range of $i$ is 1 to 374 and $T$ changes from $T_{0}$ to $T_{n}$ :

$$
\beta_{i}=\frac{S A_{i}\left(T_{0}\right)}{F_{T}\left(T_{0}\right)}
$$

where $S B_{i}(T)$ is value of the spectral acceleration of record number $i$ that scales to $T_{0}$ at period $T ; S A_{i}(T)$ is value of the spectral acceleration of record number $i$ at period $T ; F_{T}(T)$ is value of the target design spectrum at period $T ; T_{0}$ is initial period (in this research considered as $0.2 T$ ); $T_{n}$ is final period (i.e., $1.5 T)$; and $T$ is vibration period of the structure.

The objective function of the problem is to minimize the error between the averaged scale spectrum and the target spectrum in the range of $T_{0}$ to $T_{n}$. Error function $(Z)$ could be summarized as:

$$
Z=\min \left\{\sum_{T=T_{0}}^{T_{n}}\left(\sqrt{\frac{\sum_{i=1}^{7}\left[S_{i} \times S B_{i}(T)\right]^{2}}{\sum_{i=1}^{7} S_{i}^{2}}}-F_{T} P(T)\right)^{2}\right\},
$$

where $S_{i}$ is the scale factor of $n$th record.
The optimization procedure is subject to:

$$
\begin{aligned}
& S_{\min } \leq S_{i} \leq S_{\max }, \\
& S_{\min }, S_{\max }>0,
\end{aligned}
$$

where $S_{\min }$, and $S_{\max }$ are the minimum and maximum acceptable scaling factors, respectively.

Eq. (5) is a constraint for the defined optimization problem as:

$$
\sqrt{\frac{\sum_{i=1}^{7}\left[S_{i} \times S A_{i}(T)\right]^{2}}{\sum_{i=1}^{7} S_{i}^{2}}}-F_{T}(T) \geq 0
$$

for all periods $T_{0} \leq T \leq T_{n}$.

The variables (population) in this study are any arbitrary combination of 7 records and 7 scaling factors which are defined as a single "individual" or chromosome. Each individual has fourteen subdivisions to represent each variable (seven for identification of the corresponding scale factors (chromosome 1) and seven for identification of records in the database (chromosome 2). In binary-permutation GA, a length of 10 binary digits is assigned to each subdivision making the total length of each individual equal to 140 binary digits. Since the records of integers and scale factors are real numbers, optimization approaches require a combination of the processes that separates the real numbers from integer.

\section{Results}

In order to show the efficiency of the developed algorithms and their accuracy in reducing errors, the results of analysis are discussed in this section. Regarding the stochastic nature of the genetic algorithm, different results can be achieved in each run. To ensure that optimal results are not random, the program is performed for all individuals in the population and stored in memory. Then, the program runs automatically ten times with the same people and the same number of generation, and finally the generation with lowest error is selected as the final result.

Effect of each input parameter on the results was evaluated to find the optimum values through sensitivity analysis. In order to improve the performance of the proposed GAs, the results of the previous phases are used as a starting point of a new analysis. For this purpose, after the first run of each phase, the results of scale factors and the number of the earthquakes are saved in the form of $n \times 7$ matrix, and the searching space is limited to the saved values ( $n$ is the number of population). Meanwhile, in order to ensure the correct operation of the codes in reaching the minimum error, the program runs ten times for each parameter. 
Table 1. The default values for input parameters of GA recommend by Naeim et al. [4].

\begin{tabular}{cccccc}
\hline Gen & Pop & LB & UB & Pc & Pm \\
\hline 300 & 200 & 0.5 & 1.5 & 0.65 & 0.025 \\
\hline
\end{tabular}

Analysis with 10 different values is performed ten times with specific time span; consequently, 1600 analyses are carried out by applying the first and second algorithms. The best values obtained for each phase are tabulated and discussed in this section of the paper.

In the beginning, the value of the different variables is adopted based on the proposed values of Naeim et al. [4] reported in Table 1, and then the optimum value for each input is calculated. In this table, Gen stands for generation, $P o p$ for population, $L B$ for lowlevel scale factor, $U B$ for upper level scale factor, $P c$ for crossover percent, and $\mathrm{Pm}$ for mutation rate of each chromosome.

\subsection{Algorithm I: Real-permutation GA}

Analysis of real-permutation genetic algorithm is started by the base values of Table 1, then the program runs with 10 different values and 10 times for each value (the program runs 800 times). In each phase, the best result of 10 values is evaluated and reported. Finally, the best value of the parameter with the lowest error is recorded for the next operation. Likewise, the sensitivity of results to input parameters, including generation repetition, number of population individuals, lower and upper bound of the scaling factors, first and second chromosome crossover ratios, and first and second chromosome mutation probabilities, is discussed herein. At the end of this section, the optimum values of input parameters, selected records, and corresponding scale factors, obtained using binarypermutation genetic algorithm, are presented.

The effect of generation repetition on the results of the real-permutation genetic algorithm is analyzed by 10 values of generation repetition from 50 to 500 with 50 intervals. The values of other parameters are selected based on Table 1. The real-permutation genetic program is performed 10 times for each generation, and the results of the analysis are summarized in Table 2. The rows of this table represent the best results of each generation with the lowest error. Figure 5 shows the sensitivity of the function to the number of the generations. As a result, generation number of 200 with the minimum amount of error $(1.52 \%)$ can be considered as the best number of the generation. It is worth mentioning that increasing the repetition of the generation does not always lead to the error reduction as the maximum value of error could be observed for the generation number of 500 .

After selecting 200 generation repetitions, effect of the number of population individuals ranging from 50 to 500 with the interval of 50 is studied. Real-permutation genetic algorithm program was performed, overall 100 times, with the 10 values for the population individual. The best results of each individual with minimum errors are reported in Table 3. Figure 5 illustrates the effect of sensitivity function to the individual of the population in reaching the minimum error. The error attains its minimum at 200 population individuals $(1.52 \%)$ that can be adopted as an optimum number in the real-permutation GA analysis.

The analysis is repeated 10 times with 10 values, ranging from 0.1 to 1 with the interval of 0.1 for lower bound of scaling factors. Table 4 presents the best run of each generation with the minimum value of error. The results show that the value of 0.7 for lower level of the scaling factor results in $1.19 \%$ error which is the minimum value for the error. Subsequently, the value of 0.7 is adopted as optimal value of this parameter. The effect of sensitivity function on lower level of scaling factor in obtaining the minimum error is shown through Figure 5. It could be seen that the error rate for 10 selected lower levels in this study varies

Table 2. The real-permutation GA results with different numbers of generation.

\begin{tabular}{|c|c|c|c|c|c|c|c|c|c|c|c|c|c|c|c|}
\hline \multirow{2}{*}{$\frac{\text { Gen }}{50}$} & \multicolumn{7}{|c|}{ Scale factor $(S)$} & \multicolumn{7}{|c|}{ Record number } & \multirow{2}{*}{$\begin{array}{c}\begin{array}{c}\text { Error } \\
(\%)\end{array} \\
0.0291\end{array}$} \\
\hline & & & 0.69051 & & & & & 17 & 105 & 151 & 176 & 84 & 46 & 303 & \\
\hline 100 & 0.99372 & 1.07604 & 1.10019 & 1.38134 & 1.07946 & 0.82144 & 0.96091 & 338 & 64 & 183 & 280 & 69 & 288 & 167 & 0.0203 \\
\hline 150 & 1.19718 & 1.04334 & 1.21221 & & 0.75139 & 0.95958 & & 320 & 337 & 101 & 55 & 183 & 343 & 37 & \\
\hline & & & 0.95545 & & & & & 37 & 223 & & & 319 & 181 & 04 & \\
\hline 250 & & & & & & & & 69 & 288 & 32 & 142 & 303 & 251 & 233 & 0.028 \\
\hline 300 & 0.93254 & 0.86716 & 1.0221 & 1.03636 & 0.88011 & 1.15167 & 1.03224 & 176 & 361 & 270 & 64 & 253 & 264 & 137 & 0.0182 \\
\hline 350 & & & 1.02974 & & & & & 40 & 126 & 120 & 12 & 104 & 255 & 273 & 0.0167 \\
\hline 400 & & 1.26097 & 0.90698 & & 0.73636 & & & 278 & 339 & 69 & 214 & 315 & 102 & 47 & 0.0168 \\
\hline 450 & & & & & & & & 42 & 233 & 237 & 16 & 62 & 327 & 37 & 0.0155 \\
\hline 500 & 1.19063 & 0.74532 & 1.04746 & 0.83303 & 0.9817 & 1.07504 & 1.00569 & 360 & 266 & 256 & 294 & 238 & 315 & 142 & 0.0314 \\
\hline
\end{tabular}



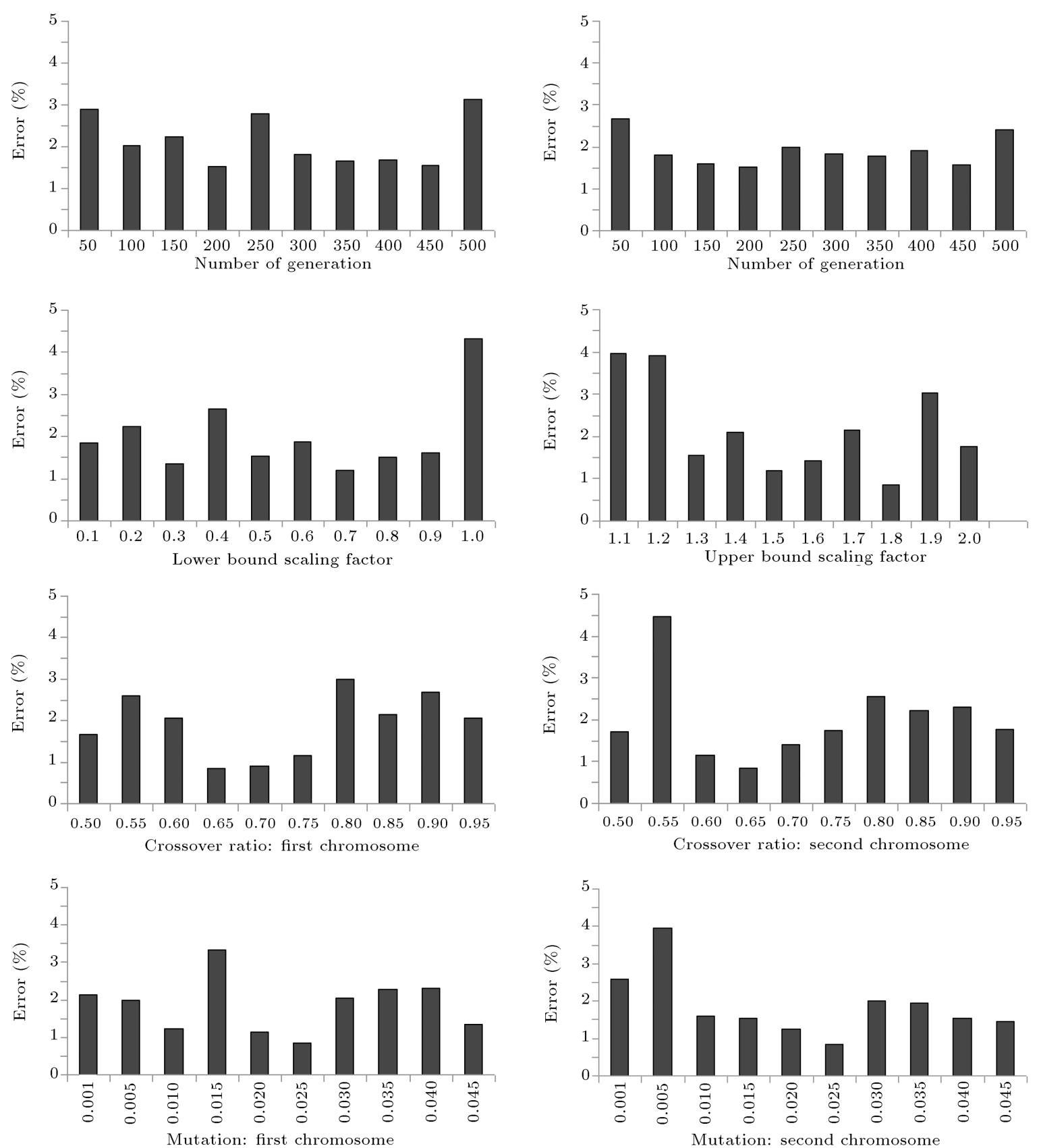

Figure 5. Error rate vs. number of generation, population size, lower and upper bounds of scaling factor, crossover and mutation ratios for the first and second chromosomes in Algorithm I.

from 1.19 to $4.32 \%$. This indicates that the range of error variation for scaling lower level is more than that of the two pervious parameters (generation repetition and individual of the population). Accordingly, lower bound of scaling factor should be selected carefully, and selecting the value larger than 0.9 is not recommended for this parameter.

A real-permutation genetic search of a 200individual population over 200 generations with lower level of 0.7 and 10 different values for upper bound of scaling factor ranging from 1.2 to 2 with the interval of 0.1 was utilized. The best results of analysis are presented in Table 5. Again, variation of error against upper bound values of scaling factor is plotted in Figure 3. Based on the results, the value of 1.8 is recommended for upper bound of scale, resulting in the error rate of 0.84 ; the selecting values less than 1.3 is not recommended (see Table 4 for more details).

For analysis of the effect of the first chromosome crossover ratio, 10 values of the probability ranged from 0.5 to 0.95 with the interval of 0.05 are considered. The optimum input values obtained for other parameters, including 200-individual population, 200 generations, lower level of 0.7 , and upper level 1.8 for scaling factor, 
Table 3. The real-permutation GA results with different numbers of population of individual.

\begin{tabular}{|c|c|c|c|c|c|c|c|c|c|c|c|c|c|c|c|}
\hline \multirow{2}{*}{$\frac{\text { Pop }}{50}$} & \multicolumn{7}{|c|}{ Scale factor $(S)$} & \multicolumn{7}{|c|}{ Record number } & \multirow{2}{*}{$\begin{array}{c}\text { Error(\%) } \\
0.0266569\end{array}$} \\
\hline & & & .26895 & & & & & 53 & 154 & 120 & 214 & 170 & 133 & 217 & \\
\hline 100 & 1.39496 & 217 & & & & & & & 226 & 312 & 336 & 279 & 259 & & \\
\hline & & & & & & & & J11 & 172 & 337 & 347 & 211 & 326 & 50 & \\
\hline 200 & 93596 & 1.11979 & 95545 & 1.44582 & 0.98199 & 0.8261 & & 37 & 223 & 117 & 354 & 319 & 181 & 64 & 495 \\
\hline 250 & 1.09612 & 1.32467 & 1.03052 & 1.32286 & 0.96022 & 1.22711 & 0.97832 & 70 & 57 & 171 & 303 & 266 & 297 & 69 & 9782 \\
\hline 300 & & & & & & & & 230 & 272 & 40 & 154 & & & & \\
\hline 350 & & & & & & & & 47 & 64 & 11 & 344 & 128 & 296 & 230 & \\
\hline 400 & & & ? 02090 & 1.18282 & 0.81593 & & & 354 & 264 & 109 & 37 & 135 & 327 & 233 & 0.0190983 \\
\hline 450 & & & & & & & & 222 & 173 & 283 & 65 & 304 & 176 & 272 & 57609 \\
\hline 500 & 0.58757 & 1.11635 & 1.1492 & 0.823 & 0.9472 & 0.87364 & 1.01132 & 176 & 60 & 264 & 34 & 350 & 183 & 315 & 0.0242025 \\
\hline
\end{tabular}

Table 4. The real-permutation GA results with different lower bound values for scaling factor.

\begin{tabular}{|c|c|c|c|c|c|c|c|c|c|c|c|c|c|c|c|}
\hline \multirow{2}{*}{$\frac{\mathbf{L B}}{0.1}$} & \multicolumn{7}{|c|}{ Scale factor $(S)$} & \multicolumn{7}{|c|}{ Record number } & \multirow{2}{*}{$\frac{\text { Error(\%) }}{0.01847}$} \\
\hline & 0.95872 & & .78216 & & 1383 & & & 70 & 11 & 249 & 338 & 176 & 359 & 327 & \\
\hline 0 & 0.79433 & 0.79769 & 0.88651 & 0.60 & & & & & 37 & 247 & 349 & 70 & 150 & & \\
\hline & & & & & & & & 315 & 65 & 286 & 181 & 249 & 64 & & \\
\hline 0.4 & 1.27646 & 0.96293 & 0223 & & 8591 & 1725 & & 54 & 313 & 254 & 267 & 349 & 251 & 8 & \\
\hline 0.5 & 0.93596 & & 0.95545 & & & & & 37 & 223 & 117 & 354 & & 181 & & \\
\hline 0.6 & & & & & & & & 233 & 316 & 288 & 161 & 249 & 64 & 239 & \\
\hline 0.7 & 1.44907 & 1.19325 & 0.84249 & 1.03641 & 1.18628 & 1.25848 & 1.14363 & 355 & 230 & 233 & 309 & 64 & 299 & 251 & 199 \\
\hline 08 & & & & & & & & 266 & 310 & 238 & 198 & 64 & 42 & & \\
\hline 0.9 & & & 1.18278 & & & & & 16 & 274 & 123 & 284 & 195 & 34 & $31:$ & \\
\hline 1 & 1.47469 & 1.10238 & 1.24134 & 1.18729 & 1.33406 & 1.31812 & 1.25494 & 72 & 151 & 286 & 110 & 288 & 161 & 109 & 0.0432 \\
\hline
\end{tabular}

Table 5. The real-permutation GA results with different upper bound values for scaling factor.

\begin{tabular}{|c|c|c|c|c|c|c|c|c|c|c|c|c|c|c|c|}
\hline \multirow{2}{*}{$\frac{\mathbf{U B}}{1.1}$} & \multicolumn{7}{|c|}{ Scale factor $(\mathrm{S})$} & \multicolumn{7}{|c|}{ Record number } & \multirow{2}{*}{$\frac{\text { Error(\%) }}{0.03968}$} \\
\hline & 0.81573 & 0.97467 & 1.01525 & 0.92242 & 0.90028 & 1.09512 & 0.88843 & 151 & 35 & 337 & 327 & 345 & 360 & 354 & \\
\hline 1.2 & 0.98782 & 1.01147 & 0.75751 & 1.02083 & 0.952 & 0.96674 & 0.74245 & 311 & 25 & 288 & 292 & 304 & 172 & 195 & 0.03908 \\
\hline 1.3 & 0.76069 & 0.99275 & 1.15384 & 0.96979 & 1.03353 & 0.99114 & 0.96064 & 37 & 100 & 352 & 296 & 172 & 327 & 321 & 0.0155 \\
\hline 1.4 & 0.95082 & 1.07996 & 1.01859 & 1.06478 & 1.04474 & 1.05825 & 1.1935 & 189 & 191 & 349 & 296 & 261 & 308 & 37 & 0.02093 \\
\hline 1.5 & 1.44907 & 1.19325 & 0.84249 & 1.03641 & 1.18628 & 1.25848 & 1.14363 & 355 & 230 & 233 & 309 & 64 & 299 & 251 & 0.01199 \\
\hline 1.6 & 1.05532 & 1.09587 & 1.3317 & 0.88843 & 1.20485 & 1.12749 & 1.19382 & 226 & 350 & 222 & 55 & 42 & 132 & 11 & 0.01428 \\
\hline 1.7 & 0.95569 & 1.26044 & 1.22885 & 1.17575 & 1.63004 & 0.95717 & 1.3219 & 227 & 125 & 150 & 337 & 360 & 251 & 172 & 0.02146 \\
\hline 1.8 & 1.41879 & 1.18875 & 1.10586 & 1.6675 & 1.26067 & 1.24039 & 1.22049 & 53 & 227 & 233 & 333 & 37 & 238 & 145 & 0.00845 \\
\hline 1.9 & 1.31692 & 1.19287 & 1.39077 & 1.02543 & 1.30858 & 1.34594 & 1.01664 & 35 & 337 & 149 & 221 & 330 & 350 & 37 & 0.03032 \\
\hline 2 & 1.21825 & 1.87066 & 0.87861 & 1.55584 & 1.40946 & 0.97095 & 1.45553 & 349 & 366 & 171 & 183 & 311 & 11 & 172 & 0.01755 \\
\hline
\end{tabular}

are fixed. Results of searching for the real-permutation genetic algorithm to determine the appropriate value of the first chromosome crossover ratio are summarized in Table 6. The effect of the sensitivity function on the first chromosome crossover ratio in terms of errors between the average response spectra with the design spectrum is plotted in Figure 5. Based on the results, the minimum rate of the error is related to the crossover ratio of 0.65 , which is equal to 0.84 . It is worth noting that the range of the error variation for different values changes from 0.84 to $3 \%$. Similar analysis is carried out for the second chromosome. The best results of each run are put in Table 7 . Figure 5 also shows the effect of the second chromosome crossover ratio in the solution of real-permutation GA. The maximum rate of success is obtained similarly for crossover ratio of 0.65 , which is corresponding to error value of $0.84 \%$.

Finally, the first and second chromosome muta- 
Table 6. The real-permutation GA results with different crossover ratios for the first chromosome.

\begin{tabular}{|c|c|c|c|c|c|c|c|c|c|c|c|c|c|c|c|}
\hline \multirow{2}{*}{$\frac{\text { Pc1 }}{0.5}$} & \multicolumn{7}{|c|}{ Scale factor $(S)$} & \multicolumn{7}{|c|}{ Record number } & \multirow{2}{*}{$\frac{\operatorname{Error}(\%)}{0.01663}$} \\
\hline & & 1.20138 & 1.11943 & 1.29848 & 1.53973 & & & 251 & 214 & 254 & 238 & 142 & 369 & 167 & \\
\hline 0.55 & & 1.42189 & & & & & & 40 & 168 & 141 & 72 & 338 & 251 & 104 & \\
\hline 0.6 & & 1.435 & 1.35734 & 1.35145 & & & & 285 & 297 & 370 & & 174 & 139 & 338 & \\
\hline 0.65 & & & 1.10586 & 1.6675 & & & & 53 & 227 & 233 & 333 & 37 & 238 & & \\
\hline 0.7 & & & & & & & & & 327 & & 176 & 12 & 104 & & \\
\hline 0.75 & & & & & & & & 221 & 313 & 176 & 66 & 72 & 183 & 371 & \\
\hline 0.8 & & & & & & & & 6 & 266 & 297 & 17 & 256 & 273 & & \\
\hline 0.85 & & & & & & & & & 337 & 180 & 64 & & 47 & & \\
\hline 0.9 & & & 1.30954 & 1.11045 & & & & 350 & 176 & 12 & 203 & 337 & 304 & 182 & \\
\hline 0.95 & 1.07011 & 1.32327 & 1.14029 & 1.13293 & 0.73074 & 1.11104 & & 343 & 87 & 230 & 149 & 173 & 37 & 238 & 0.02067 \\
\hline
\end{tabular}

Table 7. The real-permutation GA results with different crossover ratios for the second chromosome.

\begin{tabular}{|c|c|c|c|c|c|c|c|c|c|c|c|c|c|c|c|}
\hline \multirow{2}{*}{$\frac{\text { Pc2 }}{0.5}$} & \multicolumn{7}{|c|}{ Scale factor (S) } & \multicolumn{7}{|c|}{ Record number } & \multirow{2}{*}{$\frac{\operatorname{Error}(\%)}{0.01716}$} \\
\hline & 1.06749 & 1.20672 & 1.78434 & 1.43814 & 1.36098 & & & 40 & 150 & 210 & 272 & 70 & 102 & 178 & \\
\hline 0.55 & & & & & & & & 357 & 120 & 69 & 195 & 39 & 320 & & 0.0446 \\
\hline 0.6 & & & & & & & & 327 & & & & & 183 & & \\
\hline & & & & & & & & 53 & & & 333 & 37 & 238 & & \\
\hline 0.7 & & & & & & & & 171 & & 55 & 343 & & 60 & & \\
\hline 0.75 & & & & & & & & 40 & 135 & 45 & 264 & & 37 & 34 & \\
\hline 0.8 & & & 1.24863 & & & & & 45 & 37 & 238 & 103 & 349 & 101 & & \\
\hline 0.85 & & & 1.77365 & & & & & 237 & 64 & 15 & 48 & 244 & 137 & 176 & \\
\hline 0.9 & & & & & & & & 264 & 353 & 324 & 35 & 174 & 204 & 237 & \\
\hline 0.95 & 1.0659 & 1.29353 & 1.34548 & 1.5206 & 1.43483 & 1.35777 & 0.96087 & 368 & 336 & 233 & 237 & 371 & 328 & 39 & 0.01782 \\
\hline
\end{tabular}

Table 8. The real-permutation GA results with different mutation probabilities for the first chromosome.

\begin{tabular}{|c|c|c|c|c|c|c|c|c|c|c|c|c|c|c|c|}
\hline \multirow{2}{*}{$\frac{\text { UB }}{0.001}$} & \multicolumn{7}{|c|}{ Scale factor $(\mathrm{S})$} & \multicolumn{7}{|c|}{ Record number } & \multirow{2}{*}{$\frac{\operatorname{Error}(\%)}{0.02131}$} \\
\hline & & & 1.35247 & 1.363 & 1.22533 & & & 239 & 233 & 237 & 304 & 253 & 39 & 18 & \\
\hline 0.005 & & & & & & & & & & & & & & & 0.02001 \\
\hline & & & & & & & & & & 64 & 62 & & 45 & & \\
\hline & & & & & & & & 104 & 195 & 248 & 319 & 80 & 103 & & \\
\hline 0.02 & 1.44177 & 7537 & 1.18346 & 1.5019 & 1.47271 & 1.38563 & & 371 & 233 & 237 & 16 & 102 & 300 & 214 & \\
\hline 0.025 & 1.41879 & 1.18875 & 1.10586 & 1.6675 & 1.26067 & 1.24039 & 1.22049 & 53 & 227 & 233 & 333 & 37 & 238 & 145 & \\
\hline & & & & & & & & 92 & 27 & 222 & 343 & 11 & & & \\
\hline & & & & & & & & 37 & 349 & 372 & 150 & 260 & 295 & 362 & \\
\hline 0.04 & & & & & & & & 215 & 349 & 168 & 173 & 324 & 267 & 38 & \\
\hline 0.045 & 1.61693 & 1.0291 & 1.51167 & 1.02781 & 1.48533 & 1.07537 & 1.08457 & 221 & 296 & 338 & 139 & 354 & 358 & 337 & 0.01337 \\
\hline
\end{tabular}

tion probabilities with 10 different values (from 0.001 to 0.045 ) with the interval of 0.005 were utilized in realpermutation GA process. 200 individual populations over 200 generations with lower and upper levels of scale factors equal to 0.7 and 1.8 , respectively, were chosen through the analysis. The best results for the first and second chromosomes are presented in Tables 8 and 9 , respectively. The minimum amount of error is related to the mutation rate of 0.025 and is equal to $0.84 \%$ for both of chromosomes (see Figure 5 ).
The final optimum values for optimizing the controlling parameters of the first hybrid genetic algorithm are summarized in Table 10. The mean square error between is $0.84 \%$ when the first hybrid genetic algorithm is used in selection and scaling procedure. The number of selected records in terms of their number in the database along with scaling factors for each record is presented in Table 11. S factor in this table is the scaling factor obtained by GA-algorithm. Figure 6 compares the average response spectra of 7 selected 
Table 9. The real-permutation GA results with different mutation probabilities for the second chromosome.

\begin{tabular}{|c|c|c|c|c|c|c|c|c|c|c|c|c|c|c|c|}
\hline \multirow{2}{*}{$\frac{\mathbf{P ~ m 2}}{0.001}$} & \multicolumn{7}{|c|}{ Scale factor $(\mathrm{S})$} & \multicolumn{7}{|c|}{ Record number } & \multirow{2}{*}{$\frac{\text { Error(\%) }}{0.026}$} \\
\hline & & & 1.41343 & 1.53396 & 1.07803 & & & 181 & 372 & 171 & 351 & 117 & 125 & 64 & \\
\hline 0.005 & & & & & & & & 204 & 233 & 168 & 64 & 84 & 87 & 303 & \\
\hline 0.01 & 1.46765 & & 1.60828 & & & & & & 186 & 221 & 47 & 176 & 349 & 315 & \\
\hline & & & & & & & & & 145 & & 80 & & & & \\
\hline & & & & & & & & & 11 & 360 & 338 & 113 & 251 & 220 & \\
\hline & & & & & & & & 53 & 227 & 233 & 333 & 37 & & 145 & \\
\hline & & & & & & & & & 186 & 12 & 176 & 349 & & & \\
\hline & & & & & & & & & 150 & 266 & 238 & 226 & 325 & 294 & \\
\hline 0.04 & & & 1.70447 & 1.20349 & & & & & 64 & 371 & 315 & 135 & 349 & 37 & 0.01555 \\
\hline 0.045 & 1.1452 & 1.2407 & 1.25707 & 1.24822 & 1.27948 & 1.43221 & 1.70171 & 230 & 237 & 337 & 176 & 272 & 204 & 105 & 0.0144 \\
\hline
\end{tabular}

Table 10. Recommended values for input parameters of real-permutation GA in this study.

\begin{tabular}{cccccccc}
\hline Generation no. & Population & $\begin{array}{c}\text { LB } \\
\text { scaling }\end{array}$ & $\begin{array}{c}\text { UB } \\
\text { scaling }\end{array}$ & $\begin{array}{c}\text { Crossover } \\
\text { ratio 1 }\end{array}$ & $\begin{array}{c}\text { Crossover } \\
\text { ratio 2 }\end{array}$ & $\begin{array}{c}\text { Mutation } \\
\text { ratio 1 }\end{array}$ & $\begin{array}{c}\text { Mutation } \\
\text { ratio 2 }\end{array}$ \\
\hline 200 & 200 & 0.7 & 1.8 & 0.65 & 0.65 & 0.025 & 0.025 \\
\hline
\end{tabular}

Table 11. The records and scaling factors selected by the real-permutation GA.

\begin{tabular}{cccccc}
\hline No. & Record no. & Earthquake name and station & B & $\mathbf{S}$ & $\boldsymbol{\beta} * \mathbf{S}$ \\
\hline 1 & 53 & Loma Prieta, Gilroy Gavilan Coll, 067 (CDMG Station ) & 1.0541595 & 1.4134 & 1.4899 \\
2 & 227 & Northridge, Brentwood , Compup (VA Station 638) & 2.03987 & 1.1887 & 2.4248 \\
3 & 233 & Northrgle-(USC Station 900058) & 3.3443857 & 1.1058 & 3.6984 \\
4 & 333 & Whittier, Big Tujunga-Angeles, 262 (USC Station 90061) & 2.2975455 & 1.1667 & 3.8311 \\
5 & 37 & Landers, Villa Park - Serrano AV, 000 (USC Station 90090) & 13.290948 & 1.26067 & 16.7555 \\
6 & 238 & Northridge-City Hall, 360 (CDMG Station 14560) & 7.5255417 & 1.2409 & 9.3384 \\
7 & 145 & Landersbrs 000 & 3.9247014 & 1.2204 & 4.7900 \\
\hline
\end{tabular}

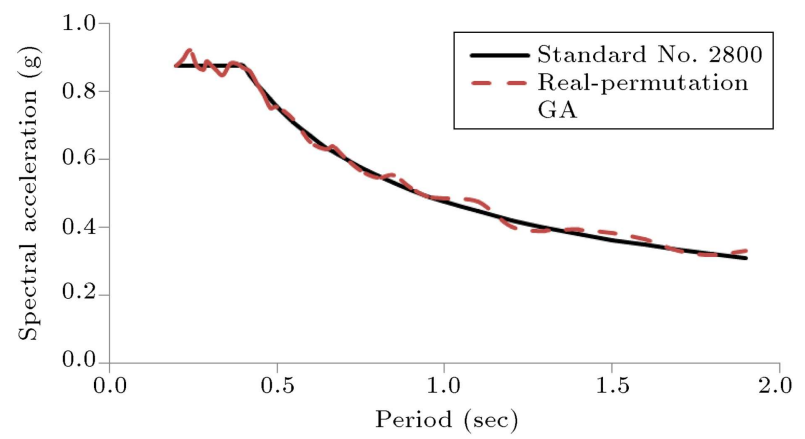

Figure 6. Comparison of average spectrum of selected-scaled records based on the real-permutation GA with target spectrum.

records with design spectrum of the Standard No. 2800. Acceleration time histories of the selected ground motion records before and after scaling procedure are provided in Figure 7.

\subsection{Algorithm II: Binary-permutation GA}

Encoding techniques in genetic algorithms are known as problem-specific techniques. Unlike the permutation encoding that every chromosome is a string of numbers, in binary encoding as the most common form of encoding in GA, the data value is converted into binary strings. In the same way as was done for the first algorithm, influence of changes of input parameters on the results of binary-permutation GA is studied in this section to identify the appropriate input parameters values needed for best estimations.

Similar range of variation for generation repetition from 50 to 500 with 50 intervals is considered for Algorithm II. The values of other parameters are selected according to Table 1 . Figure 8 shows the sensitivity of results to the number of the generations. Minimum value of error $(0.97 \%)$ has been achieved for 300 generations which can be considered as the best number of the generation. The results also show that the best number of generation in this algorithm is larger than the first algorithm, which can lead to less error value. Indeed, the range of error in binary-permutation genetic algorithm is about 0.097 to $2.19 \%$, which is smaller than the error range of real-permutation GA (1.52 to $3.14 \%)$.

As an important input parameter, the impact of population size on the proposed binary-permutation 

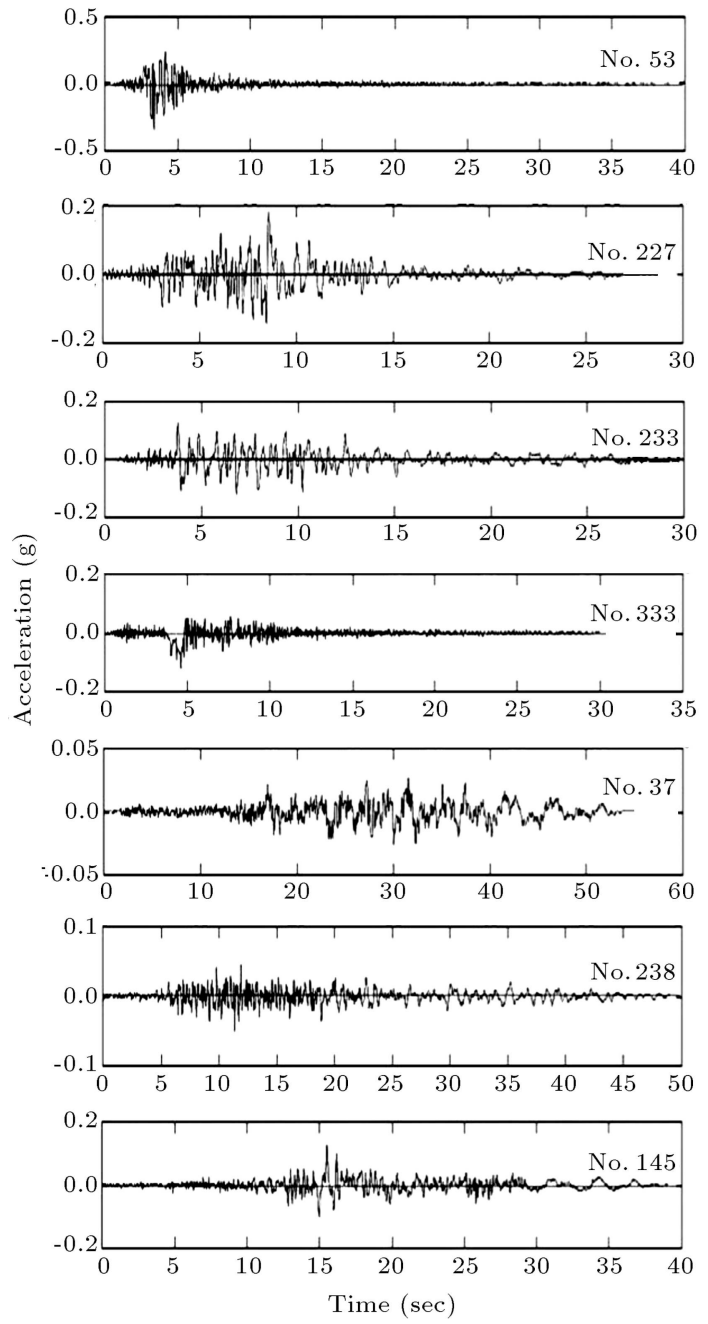

(a)
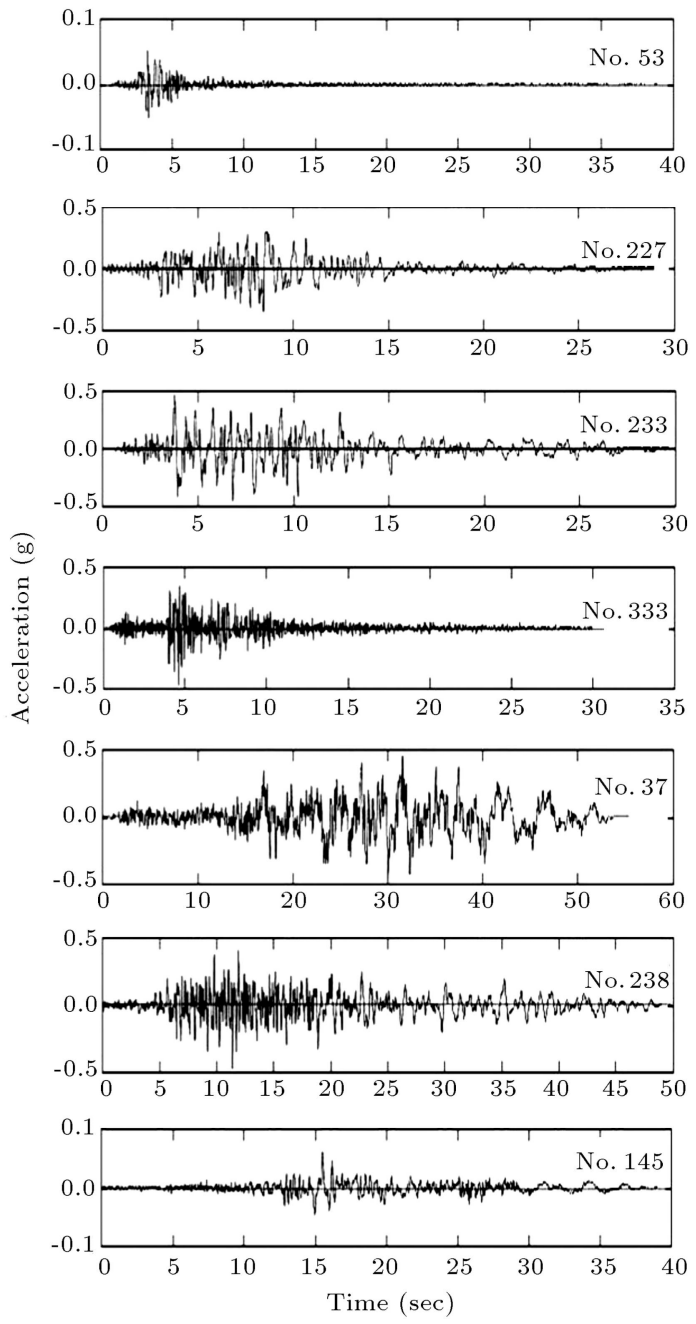

(b)

Figure 7. Acceleration time-history of selected ground-motion records real-permutation GA: (a) Before scaling and (b) after scaling.

genetic algorithm in producing minimum rate of error is evaluated herein. Population size represents the volume of the candidate solutions, and thus space of search. It controls selective pressure, population diversity; therefore, selection of appropriate value for population size will make the search effective. The population size of GA is used in the range of 50 to 500 with the interval of 50 . The minimum error is reached for 400 generations $(0.77 \%)$, and this size of population can be taken as an appropriate value for this parameter (see Figure 8). It means that unlike the first proposed algorithm, the increasing of population size to 400 in Algorithm II could reduce the error value more than $50 \%$. However, the time taken to find a good solution does not change significantly with the increase of population size from 200 to 400 in both of algorithms.

To evaluate the effect of lower bound scaling factors on the proposed algorithm efficiency, the algorithm runs 10 times with 10 values, ranging from
0.1 to 1 with the interval of 0.1 . The generation repetition and population size are fixed on 300 and 400 , respectively. Other input parameters have been selected based on Table 1 . We have summarized the results in Figure 8. The results show that the value of 0.5 for lower level of scaling factor resulted in $0.77 \%$ error could be nominated as the optimal value. The error rate for 10 selected lower levels varies from 0.77 to 2.4. The worst case (corresponding to maximum value of error) is related to the lower value of 0.1 . Such a condition is observed in the first algorithm for the value of 1 .

Similar analyses have been performed for upper bound of scaling factor by considering range of 1.1 to 2 with the interval of 0.1 . The value of 1.5 is recommended for the upper level of scaling that results in the error rate of $0.77 \%$ (see Figure 8). Accordingly, the lower and upper bounds of the optimum scale factor have been obtained as 0.5 and 1.5 , respectively; in the second algorithm, they are smaller than the 

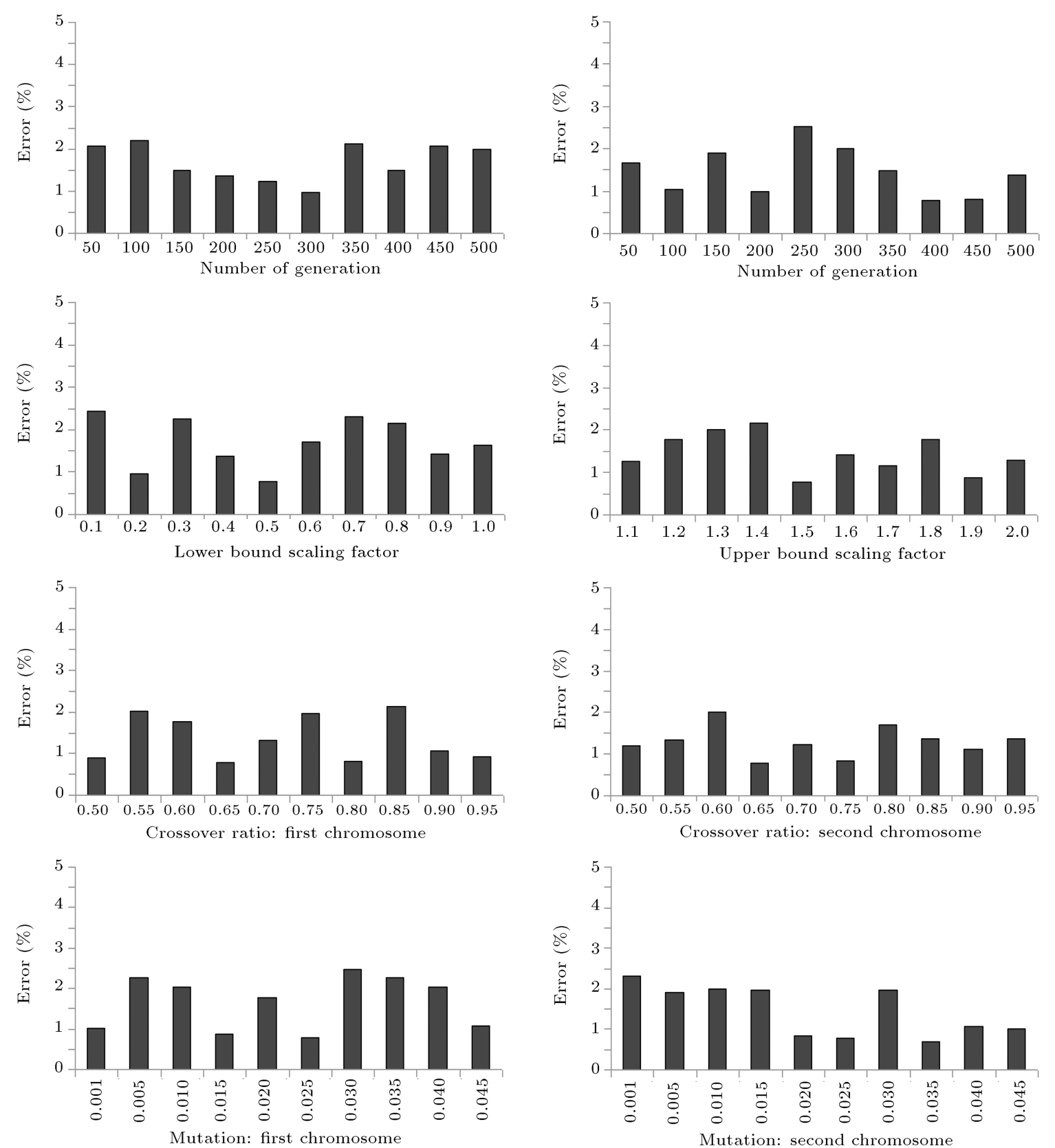

Figure 8. Error rate vs. number of generation, population size, lower and upper bounds of scaling factor, crossover and mutation ratios for the first and second chromosomes in Algorithm II.

corresponding values in the first algorithm (i.e., 0.7 and 1.8). In addition, sensitivity to these parameters is lower when the second algorithm is used.

We compared crossover ratio effects of the first and second chromosomes on converging with the best solution by considering fixed values of all other parameters mentioned above. 10 values of the probability ranged from 0.5 to 0.95 , with the interval of 0.05 , are utilized. A binary-permutation genetic algorithm with 10 values has been run 100 times to determine the first chromosome crossover rate. 100 Similar analyses have been performed for the second chromosome crossover rate. Figure 8 shows the results of sensitivity analysis to crossover rate of the first and second chromosomes. The parameter estimates show that minimum amount of error equal to $0.77 \%$ is related to the crossover rate of 0.65 for both of chromosomes.

The first and second chromosome mutation probabilities in binary-permutation GA ranged from 0.001 to 0.045 with the interval of 0.005 . We ran the algorithm 100 times the same as the pervious sections for each setting. Minimum value of the error of the first chromosome is related to the mutation probability of 0.025 and is equal to $0.77 \%$ (Figure 8). Accordingly, the optimal mutation rate of the first chromosome has the same value as for Algorithms I and II. But, for 
the second chromosome, minimum rate of the error is related to the mutation rate of 0.035 and equal to $0.68 \%$ which is different from the corresponding value of the second chromosome in Algorithm I ( i.e., 0.025).

The final optimum values for the controlling parameters of the second hybrid genetic algorithm are presented in Table 12. The average response spectrum of 7 records chosen based on Algorithm II has been plotted along with design response spectrum (or target spectrum) in Figure 9. Figure 10 shows

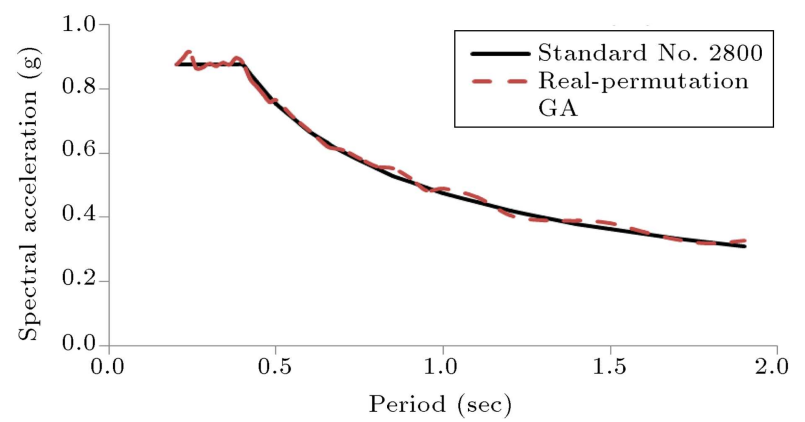

Figure 9. Comparison of average spectrum of selected-scaled records based on the binary-permutation GA with target spectrum.

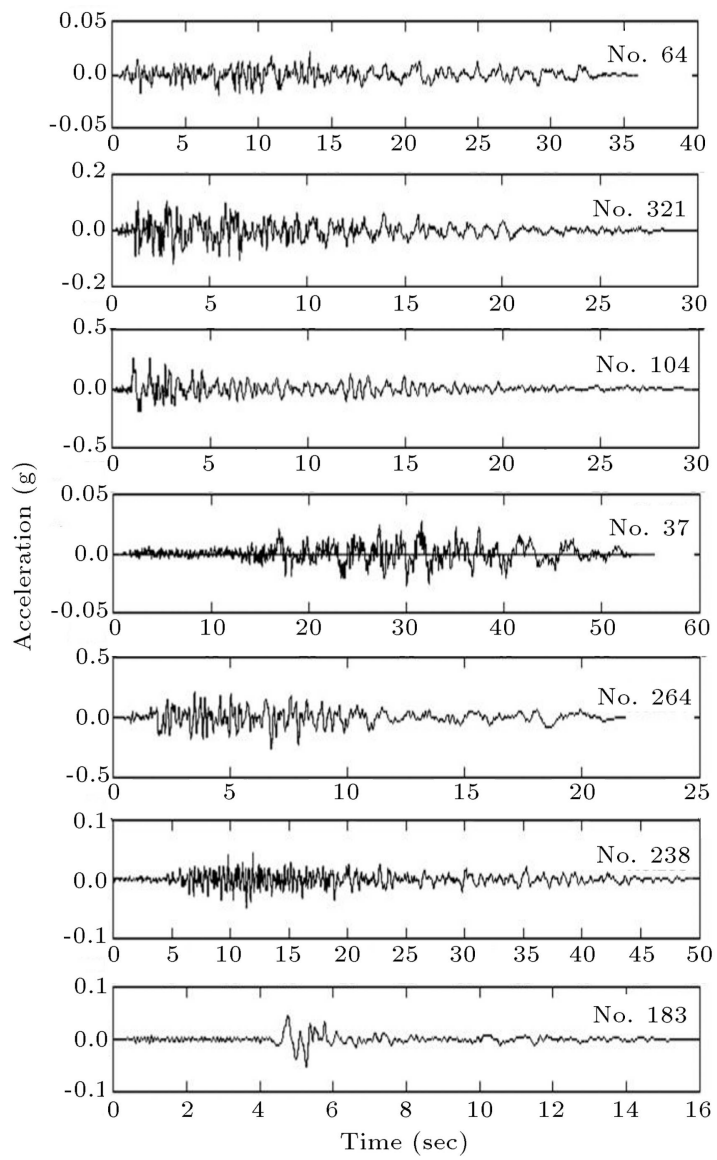

(a) the scaled and un-scaled acceleration time histories of the selected ground motions from database. Peak ground acceleration of each record is shown in the figure. The number of selected records along with the scale factors for each record is presented in Table 13 .

\section{Concluding remarks}

Different GA-based strategies were proposed to select and scale seven spectrum-compatible records among a large database of earthquake records with acceptable level of error rate. To improve the search capability of genetic algorithm in record scaling procedure, hybrid encoding was utilized in this paper through the framework of GA. In this regard, two chromosomes for the proposed hybrid genetic algorithms were chosen separately to reduce the error rate. Amount of error for real-permutation and binary-permutation coded GAs for the period range of matching $(0.25-1.9 \mathrm{sec})$ was estimated as $0.84 \%$ and $0.68 \%$, respectively, which shows higher performance of the second proposed algorithm. It is worth mentioning that the error rates of the proposed algorithms in this study are less than
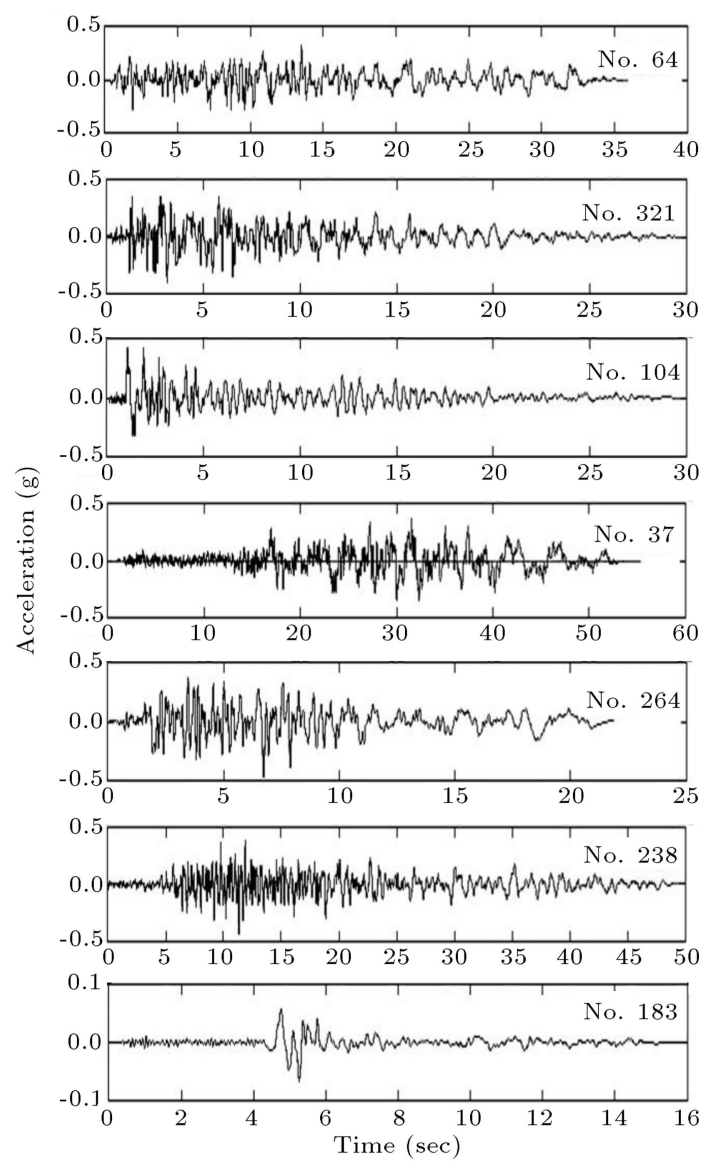

(b)

Figure 10. Acceleration time-history of selected ground-motion records by binary-permutation GA: (a) Before scaling and (b) after scaling. 
Table 12. Recommended values for input parameters of binary-permutation GA in this study.

\begin{tabular}{cccccccc}
\hline $\begin{array}{c}\text { Generation } \\
\text { no. }\end{array}$ & Population & $\begin{array}{c}\text { LB } \\
\text { scaling }\end{array}$ & $\begin{array}{c}\text { UB } \\
\text { scaling }\end{array}$ & $\begin{array}{c}\text { Crossover } \\
\text { ratio 1 }\end{array}$ & $\begin{array}{c}\text { Crossover } \\
\text { ratio 2 }\end{array}$ & $\begin{array}{c}\text { Mutation } \\
\text { ratio 1 }\end{array}$ & $\begin{array}{c}\text { Mutation } \\
\text { ratio 1 }\end{array}$ \\
\hline 300 & 400 & 0.5 & 1.5 & 0.65 & 0.65 & 0.025 & 0.035 \\
\hline
\end{tabular}

Table 13. The records and scaling factors selected by the real-permutation GA.

\begin{tabular}{ccccccc}
\hline No. & $\begin{array}{c}\text { Record } \\
\text { no. }\end{array}$ & Earthquake name and station & B & S & $\boldsymbol{\beta} * \mathbf{S}$ \\
\hline 1 & 64 & Morgan Hill, Fremont Mission SJ, 345 (CDMG Station 57064) & 18.611 & 0.8392 & 15.6183 \\
2 & 321 & San Fernando 020971 1400, Palmdale Fire Station, 120 & 2.539 & 1.33969 & 3.4018 \\
3 & 104 & 2San Fernando, Castaic Old Ridge Route, 291 (CDMG Station 24278) & 1.339 & 1.19501 & 1.6000 \\
4 & 37 & Landers, Villa Park - Serrano AV, 000 (USC Station 90090) & 13.290 & 1.01906 & 13.5442 \\
5 & 264 & Northridge EQ 11794, 1231, Coldwater Canyon, 270 & 1.226 & 1.45992 & 1.7909 \\
6 & 238 & Northridge 011794 1231, LB - City Hall, 360 (CDMG Station 14560) & 7.525 & 1.15787 & 8.7135 \\
7 & 183 & Livermorb-A3E146 & 8.469 & 1.48631 & 12.5887 \\
\hline
\end{tabular}

the developed conventional binary genetic model of Naeim et al. [4], reported as $3.12 \%$. The computational efficiency of the proposed model is also better than the solution quality of the refined harmony search for optimal scaling and selection of accelerograms with minimal error of $5 \%$ [31]. It is worth noting that this study has tried to present a new insight into GAbased record selection procedure, and all site class records could be used in the framework of designed GA.

Based on the sensitivity analysis with the proposed algorithms, the following conclusions can be drawn:

- An accurate evaluation of records scaling procedure is strictly connected to careful estimates of input parameters used in the GA analysis;

- Increasing the generation repetition and the individual of the population not always leads to analysis error reduction;

- Response sensitivity to the number of the population and generation repetition in the first algorithm is less among others, as the error variation range for the first and second parameters are $1.52-2.6 \%$ and $1.52-3.14 \%$, respectively;

- The sensitivity of the binary-permutation GA results to input parameters variations is less than realpermutation GA, which is very important for future use of such algorithms;

- The maximum sensitivity is related to the chromosome crossover rate in the first algorithm, where the error rate of this parameter increases from 0.55 to $4.46 \%$.

\section{References}

1. Iranian Code of Practice for Seismic Resistant Design of Buildings, Standard No. 2800. 3rd Ed., Building and Housing Research Center (2005).

2. Gehla, P., Douglas, J. and Seyedi, D. "Influence of the number of dynamic analyses on the accuracy of structural response estimates", Earthquake Spectra, 31(1), pp. 97-113 (2015).

3. Kayhan, A.H., Armagan, K.A. and Irfanoghlu, A. "Selecting and scaling real ground motion records using harmony search algorithm", Soil Dynamics and Earthquake Engineering, 31(7), pp. 941-953 (2011).

4. Naeim, F., Alimoradi, A. and Pezeshk, S. "Selection and scaling of ground motion time histories for structural design using genetic algorithm", Earthquake Spectra, 20(2), pp. 413-426 (2004).

5. Katsanos, E.I., Sextos, A.G. and Manolis, G.D. "Selection of earthquake ground motion records: a state-ofthe-art review from a structural engineering perspective", Soil Dynamics and Earthquake Engineering, 30, pp. 157-169 (2010).

6. Abrahamson, N.A. "Non-stationary spectral matching program", RSPMATCH, User Manual (1993).

7. Bommer, J.J. and Acevedo. A.B. "The use of real earthquake accelerograms as input to dynamic analysis", Journal of Earthquake Engineering, 8(1), pp. 4391 (2004).

8. Shome, N., Cornell, C.A., Bazzurro, P. and Carballo, J.E. "Earthquakes, records and nonlinear responses", Earthquake Spectra, 14(3), pp. 469-500 (1998).

9. Lee, L.H., Lee, H.H. and Han, S.W. "Method of selecting design earthquake ground motions for tall buildings", Structural Design of Tall Buildings, 9(3), pp. 201-213 (2000). 
10. Iervolino, I. and Cornell, C.A. "Record selection for nonlinear seismic analysis of structures", Earthquake Spectra, 21(3), pp. 685-713 (2005).

11. Dhakal, P.R., Mander, B.J. and Mashiko, N. "Identification of critical ground motions for seismic performance assessment of structures", Earthquake Engineering and Structural Dynamics, 35, pp. 989-1008 (2006).

12. Beyer, K. and Bommer, J.J. "Selection and scaling of real accelerograms for bidirectional loading: a review of current practice and code provisions", Journal of Earthquake Engineering, 11(1), pp. 13-45 (2007).

13. Iervolino, I., Maddaloni, G., Cosenza, E. and Manfredi, G. "Selection of time histories for Bridge design in Eurocode 8", In: Proceedings of 1st US-Italy Seismic Bridge Workshop, Italy (2007).

14. Reyes, J.S. and Kalkan, E. "How many records should be used in an ASCE/SEI-7 ground motion scaling procedure?", Earthquake Spectra, 28(3), pp. 1223-1242 (2012).

15. Wang, J.-P., Huang, D., Cheng, C., Shao, K., Wu, Y. and Chang, C. "Seismic hazard analyses for Taipei city including deaggregation, design spectra, and time history with excel applications", Computers and Geosciences, 52, pp. 146-154 (2013).

16. International Code Council (ICC) International Building Code, Falls Church, VA (2000).

17. "Eurocode 8 design of structures for earthquake resistance, Part 2: Bridges", Final draft pr EN1998, European Committee for Standardization, Brussels (2003).

18. Roy, R., Thakur, P. and Chakroborty, S. "Scaling of ground motions and its applications to planasymmetric structures", Soil Dynamics and Earthquake Engineering, 57, pp. 46-67 (2014).

19. Nicknam, A., Yazdani, A. and Yaghmaei-Sabegh, S. "Predicting probabilistic-based strong ground motion time series for citadel of Arg-e-Bam (south-east of Iran)", Journal of Earthquake Engineering, 13(4), pp. 482-499.

20. Yaghmaei-Sabegh, S. and Lam, N. "Ground motion modelling in Tehran based on the stochastic method", Soil Dynamics and Earthquake Engineering, 14(4), pp. 525-535 (2010).

21. Silva, W. and Lee, K. "State-of-the-art for assessing earthquake hazards in the United States", Report 24, WES RASCAL code for synthesizing earthquake ground motions, Miscellaneous Paper S-73-1. U.S. Army Engineer Waterways Experiment Station, Vicksburg (1987).

22. Fahjan, Y.M. "Selection and scaling of real earthquake accelerograms to fit the Turkish design spectra", Teknik Dergi, 19(3), pp. 4423-4444 (2008).

23. Watson-Lamprey, J. and Abrahamson, N. "Selection of ground motion time series and limits on scaling", Soil Dynamics and Earthquake Engineering, 26, pp. 477-82 (2006).
24. Kwon, O.S., Sextos, A.G. and Elnashai, A.S. "Liquefaction-dependent fragility relation- ships of complex bridge-foundation-soil systems", In: Proceedings of International Conference on Earthquake Engineering and Disaster Mitigation., Jakarta, Indonesia (2008).

25. Hancock, J.J., Watson-Lamprey, J., Abrahamson, N.A., Bommer, J.J., Markatis, A., McCoy, E. and Mendis, R. "An improved method of matching response spectra of recorded earthquake ground motion using wavelets", Journal of Earthquake Engineering, 10(1), pp. 67-89 (2006).

26. Stewart, J.P., Chiou, S.J., Bray, R.W., Graves, P., Somerville, G. and Abrahamson, N.A. "Ground motion evaluation procedures for performance-based design", PEER report 2001/09, Pacific Earthquake Engineering Research Center, University of California, Berkeley (2001).

27. Bommer, J.J. and Scott, S.G. "The feasibility of using real accelerograms for seismic design", In: Elnashai AS, Antoniou S, Editors., Implications of Recent Earthquakes on Seismic Risk, Imperial College (2000).

28. Bolt, B.A. and Abrahamson, N.A. "Estimation of strong seismic ground motions", In: Lee W.H.K, Kanamori, H., Jennings, C.P., Kisslinger, C., Eds., International Handbook of Earthquake and Engineering Seismology, Part B, Academic Press, San Diego, pp. 983-1001 (2003).

29. Lamberti, L. "An efficient simulated annealing algorithm for design optimization of truss structures", Computers \& Structures, 86(19), pp. 1936-1953 (2008).

30. Gopalakrishnan, K. "Particle swarm optimization in civil infrastructure systems: State-of-the-art review", Metaheuristic Applications in Structures and Infrastructures, pp. 49-76 (2013).

31. Shahrouzi, M. and Sazjini, M. "Refined harmony search for optimal scaling and selection of accelerograms", Scientia Iranica, 19(2), pp. 218-224 (2012).

32. PEER, N.G.A., Strong Motion Database Pacific Earthquake Engineering Research Center Database http://peer.berkeley.edu/smcat/

33. Holland, J., Adaptation in Natural and Artificial Systems, an Introductory Analysis with Application to Biology, Control and Artificial Intelligen', Ann Arbor, The University of Michigan Press (1975).

34. Camp, C.V., Pezeshk, S. and Cao, G. "Optimized design of two-dimensional structures using a genetic algorithm", J. Struct. Eng., 124(5), pp. 551-559 (1998).

\section{Biographies}

Saman Yaghmaei-Sabegh obtained his $\mathrm{PhD}$ from Iran University of Science and Technology and was awarded the Elite Prize by the university in 2006 and 2007 years. He is currently an Associate Professor at The University of Tabriz (Department of Civil Engineering) and has been Visiting Scholar to The 
University of Melbourne, Australia, since 2007. He is a member of the Iranian Earthquake Engineering Association. He has published 40 technical articles and won award in the 14th International Conference on Earthquake Engineering, in 2008, as a young researcher.

Samaneh Karami received his MSc in Structural Engineering from East Azarbaijan Science \& Research Branch, Islamic Azad University, Tabriz. Dissertation title of Karami was "Selecting Appropriate Earthquake
Records for Dynamic Analyses of Structures Using Genetic Algorithm". Her research interest includes structural dynamics and earthquake resistant design of structures.

Mazdak Hosseini-Moghadam received his MSc in Structural Engineering from East Azarbaijan Science \& Research Branch, Islamic Azad University, Tabriz. Her research interest includes structural dynamics and optimization problems. He is studying master of science at Linnaeus University 